\title{
Safety Navigation Control of Huangshi Bridge
}

\author{
Tongtong Lu ${ }^{1, a, *}$, Zeyuan Shao ${ }^{1, b}$, Huachao Peng ${ }^{1}$ and Wanzheng $\mathrm{Ai}^{2, \mathrm{c}}$, Honggang Zhang ${ }^{2}$ \\ ${ }^{1}$ Marine College, Zhejiang Ocean University, Zhoushan, Zhejiang, P. R. China \\ ${ }^{2}$ Marine College, Zhejiang Ocean University, Zhoushan, Zhejiang, P. R. China \\ a 2215795491@qq.com, b1023874516@qq.com, c aiwanzheng@163.com \\ *corresponding author
}

Keywords: Bridge area; Ships; Security; Navigation; Control.

Abstract: Based on the analysis of the hydrological conditions, navigable conditions and navigable accidents of Huangshi Bridge, this paper puts forward the safety navigable control measures of Huangshi Bridge .

\section{Introduction}

Huangshi Yangtze River Bridge is a super large bridge on National Highway 318, located in Huangshi City, Hubei Province, in the middle reaches of the Yangtze River. The length of the bridge is 2580.08 meters, the length of the main bridge is 1060 meters and the width of the bridge is 20m.Yellowstone bank approach bridge 840.7 meters long, consisting of continuous box girder bridge and bridge deck continuous T-beam bridge; Xishui shore approach bridge is 679.21 meters long and consists of a continuous T-beam bridge on the deck. The main pier adopts $28 \mathrm{~m}$ diameter double-wall steel cofferdam and $16 \Phi$ 3-meter bored cast-in-place pile foundation, which has high anti-ship impact capability. Navigable clearance 200x24 meters, can accommodate 5000 tons of single ships or 32000 tons of large fleet up and down navigation. However, since the construction of the bridge, there have been many accidents, and have been cited as teaching materials with improper distribution of bridge holes.[1].

\section{Analysis of hydrological conditions in bridge area}

When water flows through Daijiazhou bend, water potential is high on the left, low on the right, and when two straight waterways converge in the tail of Daijiazhou, through the deflecting flow at the head of Tongfengji, the mainstream pushes pressure from the left bank to the right bank bend. The flow velocity of water increases with the rise of the water level. The higher the water level is, the greater the deflection of the mainstream towards the right bank. In the dry season, the velocity of navigation bridge hole is usually about $1.0 \mathrm{~m} / \mathrm{s}$, the middle flood stage is about $2-3 \mathrm{M} / \mathrm{s}$, and the high flood level period can generally reach 3-4m/s.[2].

Table 1

\begin{tabular}{|c|c|c|c|c|c|c|c|c|c|c|c|c|}
\hline Month & 1 & 2 & 3 & 4 & 5 & 6 & 7 & 8 & 9 & 10 & 11 & 12 \\
\hline $\begin{array}{c}\text { Maximum } \\
\text { water } \\
\text { level / m }\end{array}$ & 3.91 & 2.77 & 7.81 & 8.17 & 7.83 & 12.89 & 15.39 & 10.37 & 8.86 & 10.31 & 8.84 & 3.55 \\
\hline $\begin{array}{c}\text { Minimum } \\
\text { water } \\
\text { level / m }\end{array}$ & 2.91 & 2.08 & 2.83 & 7.10 & 7.07 & 7.24 & 10.58 & 8.74 & 7.76 & 8.25 & 3.58 & 1.57 \\
\hline $\begin{array}{c}\text { Mean } \\
\text { water } \\
\text { level / m }\end{array}$ & 3.39 & 2.43 & 4.83 & 7.72 & 7.36 & 9.43 & 13.45 & 9.49 & 8.30 & 9.62 & 5.62 & 2.35 \\
\hline
\end{tabular}


According to the analysis, some larger draught vessels are difficult to pass through this section of the water area, and ships with smaller draught should also pay attention to the time of passing through the bridge area. The water level is low in November, December, January, February and March. When the water level is lowered: 1.The ship resistance increases and the ship speed decreases;2. ship hydrodynamic force and torque increase, transverse movement and steering are diffcult;3. The sinking and the trim of the hull has serious change; 4 . Violent vibration of the hull; 5. Changes in ship maneuverability. Therefore, ships in the low water level navigation should pay attention to adjust the ship maneuvering, adapt to water level changes. Companies and ships should be flexible in scheduling to ensure the safe and economical navigation of ships in the bridge area.

\section{Analysis of accident in Bridge area}

\subsection{Crew}

I. Crew does not have strong sense of responsibility, weak in sense of safety. Captain of the shift, in the event of bad weather conditions, cannot correctly distinguish the route, and pose a danger with the sense of navigation. If the operator on duty is not familiar with the specific situation of the river section of Daijiazhou Waterway Regulation Project, and navigates boldly, it is an important cause of the accident. If the storage position of household coal is not correct, too close to the main engine exhaust pipe leads to the coal temperature is too high, resulting in a fire. II. The crew should be improperly disposed of, in case of urgent situation. In the course of turning and anchoring for avoiding wind, the ship loses control, the driver on duty operated improperly in face of danger, and does not make sound and display the light signal according to the regulations, which results in the collision with the ship sailing upstream.III. The crew carelessly watched and sailed against the rules. The driver on duty fails to maintain the normal lookout during the voyage and fails to take effective measures to avoid the accident in time when he cannot judge the dynamic of the front ship. For example, when sailing upstream, the ship occupies the route of ships sailing downstream and does not take the initiative to avoid the ship sailing downstream, resulting in a collision accident. IV. Key equipment operation is unfamiliar. If the captain uses the navigational aids improperly, and does not make the relevant navigational aids play their due role in a very urgent situation.

\subsection{Ships}

I. The ship did not go through any formalities of examination and approval and made sand mining from the river at night. Sometimes it may lead to the collision of the other ship and the sand suction pipe of the ship, resulting in an accident. II. The ship's staffing do not meet the statutory requirements. The minimum number of safety personnel approved in the Ship's Minimum Safety Personnel Certificate is 7. After verification, there are only two crew members on the ship during a certain voyage.

\subsection{Corporate management}

Shipping companies are not in place for shipping management, and fail to effectively fulfill the responsibility of the main body of safety management. At present, the shipping companies that violate the regulations and rules through the bridge navigation ships basically belong to the shipping companies that have not established a safety management system, and the company has not implemented the management of ship dynamics, personnel deployment, navigation safety, regular boarding and inspection and so on. The problem was exposed in many accidents. [3].

\subsection{Navigational environmental aspects}

I. Factors of waterway regulation engineering. After the riprap revetment project in the Daijiazhou waterway, there are a large number of remnants outside the channel, and there is no obvious warning sign, which is also an important cause of the accident. II. Factors of water level and water flow. Because of the influence of the current and the improper operation of the driver on duty, the ship is out of control, which indirectly causes the collision accident. If there is a ship sailing to the Gepaiji waterway, the discharge under the three Gorges increases and submerges the 
submerged reef, which results in the sinking of the ship after touching the bottom of the ship by the submerged reef .III. Factors hindering navigation sand mining. The main reason of collision accident is unauthorized sand mining operation of a ship in the waterway. IV. Bad weather condition. Strong winds, heavy rain, fog and other bad weather conditions occur from time to time. These people cannot predict and control the weather, making it more difficult to operate ships, especially when vessels sail to the waters of the bridge area, which causes a great risk to ships and bridges. [4].

\subsection{Bridge aspects}

I.With the development of shipping industry and the development of shipping capacity, the tonnage of new ships is increasing, and the clearance height of inland bridges can no longer meet the navigation needs of large tonnage ships. Therefore, the low clearance height of the bridge has become an important reason for ship collision in recent years.[5]. II. After the completion of the bridge, the existence of bridge piers has formed another test of navigation safety. The main characteristics of the flow around the pier are the relatively strong horseshoe vortex system around the pier. This will greatly increase the difficulty of ship maneuvering, and causes also a greater risk when the ship navigates in the bridge area.[6].

\section{Safety and navigation control measures}

\subsection{Strengthening regulation}

We should strengthen the monitoring of accident prone areas. When the medium and low water level alternates, the drivers and pilots are reminded of paying attention to lookout during the navigation, to drive carefully to avoid stranding and to continue to do a good job in monitoring the key waters of the Yellowstone Bridge by giving full play to the role of modern regulatory equipment such as VTS, CCTV, electronic cruising, etc. Strictly enforce traffic control measures such as shipping ban, navigation restriction and speed limit to ensure that key water areas are effectively monitored and detected and hidden dangers are eliminated. The relevant units should step up the monitoring and punishment of vessels in the waters of the navigation bridge area. In addition to the measures already taken, they should also adopt the method of on-site spot monitoring on the spot of patrol vessels to regulate the vessel traffic flow. Ships that do not comply with the provisions of the report and do not navigate in accordance with the provisions shall be dealt with seriously.[7].All vessel units, vessel owners and operators shall strictly abide by the relevant provisions of the Law of the People's Republic of China on Safety in production and the Regulations of the People's Republic of China on the Safety of Inland River Traffic, further implement the responsibility system for safety management, strengthen the safety education and training of the crew, improve the safety awareness of the crew, and match the qualified crew members according to the rules of manning. Since April 26, 2016, the Daijiazhou Yuangang waterway has been closed, the direct port waterway has been operated by two-way navigation, and vessels sailing upstream and downstream have been navigated to the right respectively, and they have paid close attention to the safety warning information issued by the maritime authorities and paid close attention to the developments of the ships around them, take effective measures to avoid safety as soon as possible. The ship should pay attention to the information of the waterway ban in the bridge area, avoid unnecessary risks and losses when planning the voyage. Besides, for some cases that interfere with normal navigation on the waterway, 1.The prohibition of ferries when necessary; 2.Strengthen publicity, warn and urge ships to implement the relevant preventive measures.

\subsection{Improving the quality of drivers}

First of all, the crew needs to raise the awareness of the law, to avoid illegal but not aware of the situation. For serious unsafe acts or troublemakers resulting from non-compliance with laws, regulations, rules and trade regulations, direct coercive measures shall be taken to compel him to 
fulfil his obligations and to assume responsibility, and vice versa, laws, regulations, rules and regulations, and trade rules have lost their seriousness.[8].Also, through quality education and training, make the crew understand the law, use the law, abide by the law and maintain the law. Be careful not to overloaded navigation, driving with false license, unlicensed driving, over-route navigation and irregular offshore operations when the voyage is carried out; Through skills training, enhance the professional skills of the crew, prevent the occurrence of cases such as unable to operate navigational aids and unfamiliar with the basic affairs of the ship, and improve the ability to handle accidents correctly in the event of emergency, etc. In order to check whether the quality of the crew is up to the standard, it is necessary to regularly carry out the assessment, set up appropriate assessment indicators and standardize the basic quality of the driver. When vessels sail in the waters of construction operations, they should strengthen their lookout, exercise caution over operation, strictly follow the navigation channels marked by navigation marks, abide by the provisions of the Rules for Divided Navigating in the Lower Reaches of the Yangtze River, and ban overtaking, simultaneous advance and navigating with engine stopped. Ships with relatively fixed operation can ensure their own safety, the impact on navigation safety is also relatively small as long as the operation in the specified construction area, and according to the provisions of the suspension of the corresponding light type.[9].Crossing the construction work area is forbidden. Ships shall be berthed at wharves berths or anchorages berthing areas and operating areas.

\subsection{Reasonable arrangement of pilotage / tug}

For some large ships and ships with poor operating performance, they will have difficulty to cross the waters of the bridge area, so it is necessary to arrange some pilotage measures to help the ship navigate safely. But it is worth noting that it is not the arrangement after pilotage can be carefree to avoid accidents. The following points should be noted in pilotage: 1. Navigation in accordance with the regular method of navigation. Individual pilots will think that they are very familiar with the waters and take shortcuts away from the safe position in order to save time. They should determine the appropriate safe distance according to the location of dangerous objects to avoid causing loss of persons and goods; They should use the visual survey method in navigation, pay attention to correct the pressure difference of air flow at any time, and grasp the accurate position in time. When turning, they should call the course first, and pay attention to whether the helmsmen carry out or not, and then find out light floating or shore mark of the ship head. We must not call only the rudder angle, instead of the course, which is especially important in the case of poor visibility.[10].2. Pay attention to the correct approach in emergency response. Rudder orders, bell orders, etc. issued in case of emergency must be clear, pay attention to whether the rudder steering is in place and whether the rudder angle indicator or bell indicator is incorrect. After avoiding, the ship should return to the original route in time, to verify the course and position. 3 . Timely open navigational aids. When the visibility is low, the navigational aids should be opened in advance, which is conducive to the early and timely discovery of the location of the other ship, to grasp the information of other ships, so that the ships can be coordinated as soon as possible to avoid, and to ensure the safe navigation of the ship.There are several points to be noted when using tugs to assist ships in navigating in order to ensure the safe navigation of ships: 1 . Assist the big ship to cross the bend. When bending, due to the difference between the front and the tail flow, the external force transshipment torque is produced, which often exceeds the rudder force transshipment moment, which causes the bow (ship head) not to turn around. A tug boat should be provided on one side of the concave side of the bend, to use in the event of failure to turn around one's own rudder or in the event of any other accident.[11].2. Assist the ship in adjusting speed. There is a speed limit for ships in the waters of the bridge area. It is easy to overspeed when the ship is sailing along the water. In order to control the speed of the ship, a tugboat can be carried at the stern.3. Tug boat operation in case of emergency. Under the emergency of near collision, stranding, out of control ship and so on, tugboat is a powerful helper to save the ship out of danger. In the course of handling these accidents, we should pay attention to the correct command and be prepared to consider carefully such issues as whether the tug's position is safe, whether the tug is effective 
and whether the tug is in place, so as to avoid temporary confusion, panic, cause unnecessary damage.

\subsection{Enhancing understanding of the waters of the bridge area}

All shipping companies and shipping units should pay close attention to changes in waterways and meteorological and hydrological conditions during flood periods, and timely collect the safety early warning, safety alerts, and safety information issued by the marine departments of the Yangtze River Marine Affairs Bureau and Yellowstone Bureau. Please also listen to the security information broadcasted by the VHF radio station of the Yangtze River Communications Administration.VHF channel daily broadcast time:11:00:00, 17:00:00, 22:00:00. Such as: Wuhan Central Meteorological Station issued a strong wind blue warning signal at 05:42 on December 16, 2017. It is expected that, in addition to Enshi, there will be four to five grades of northerly winds and gusts of 6 to 7 from north to south in our province today. Please take precautions.[12].Vessels navigating in the waters of the bridge area shall take note of the following: 1.According to the site conditions, in bad weather, do a good job of safety protection, all safety measures must be strictly implemented to ensure the ship. 2.Vessels are advised to pay close attention to weather changes and take preventive measures to ensure the safe navigation of ships in inclement weather. Anchorage in the nearest water area should be chosen when necessary, but it should be carried out on the premise that there are no hidden dangers to the safety of itself and other ships. 3. Ferries in navigation areas need to enhance contact with maritime authorities and, where necessary, implement a ban on navigation.

\section{Concluding remarks}

In the course of ship navigation, the safe route is not invariable, but it is made and modified by synthesizing the hydrometeorological condition of waterway, the change of waterway and surrounding environment as well as the quantity of passing ship. So the crew in Huangshi Bridge must always maintain vigilance, achieve the above points, and give safety navigation the priority, when navigating through this narrow and accident-prone channel; from the point of lookout to ship operation, the crew should ensure legal driving, and skillful ship skills will help the crew correctly and flexibly navigate the ship safely across the channel. In order to ensure safety, the crew and all the personnel, units and organizations concerned with the ship should work together to erect a strong barrier in the navigation of the ship.

\section{References}

[1] Li Tao. Study on the Integration of reinforcement Design and Construction Monitoring of Prestressed Concrete Continuous Rigid Frame Bridge [D] .Changan University, China (in Chinese).

[2]Liu Mingjun, Liu Xian-dong, Qi Chuanxin. Study on Pilotage Technology of Ships (teams) through Huangshi Bridge [J] .Marine technique 1999 / 01: 2-5.

[3]Zheng Linfeng. Reflections on Navigable Safety Management in Inland River Bridge Area [J] .Zhujiang River Water Transport Co., Ltd.

[4]Luo Zhongjun, Tu Peng. Consideration on the Prevention of Ship Collision and Bridge Accidents in Navigable Waters of Bridge Area [J] .Zhujiang River Water Transport, 2011 1, 06-0 0: 43-46.

[5]Zhang Wei, Chen Zhoufeng. Study on vessel safe Navigation system in Bridge area [J] .Traffic Information and Safety (2010) (in Chinese).

[6]Dong Chunhui.Study on the Determination method of Navigation Clearance Scale of Crossing River Bridge [D] .Dalian Maritime University, China 2009.

[7]Fan Hao. Regulation of Navigation Order of Ships in the Waters of the Zhujiang River Humen Bridge [J] .Waterway Management (in Chinese): 08: 36-38 (in Chinese). 
[8]Cui Yinhong. Ways to Improve the Quality of Crew Members [J] .China Waterway 2009 11: 27.

[9]Kong Xianwei, Zhang Shuai, Wang Guanming, Xue Tao .Analysis of the influence of Construction ship Operation on Navigation Safety [J] .Tianjin Navigation ship 201301U: 12-14.

[10]Zhang Guanglei, Huang Jinbin. Key points for Ship Safety Manipulation in Narrow Waterway of the Yangtze Estuary in Shanghai [J] .Marine Transportation Administration (in Chinese): 2014 / 36 / 02N: 9-12 (in Chinese).

[11]Li Yong. The Use of Escort Tugs in Narrow Waterways [J] .Pearl River Water Transport 2014 12: 21-22.

[12] Huangshi Marine Bureau Meteorological Grade 4 (Blue) Water Traffic Safety warning No. 17 / 147 [Z] .2017-12-05 http://www.cjmsa.gov.cn/9/368/2/39/57/5643423.html 